\title{
Comparison between continuous and intermittent submaximal exercise at the intensity of maximal fat oxidation $^{1}$
}

\author{
Gökhan İpekoğlu ${ }^{2}$ \\ Şükrü Serdar Balcı ${ }^{3}$
}

\begin{abstract}
The aim of the study was to determine the rate of fat oxidation during continuous and intermittent acute endurance exercise. Eleven healthy untrained men participated in this study. Subjects performed Bruce protocol test on cycle ergometer to determine maximal oxygen consumption $\left(V_{2 \max }\right)$. The exercise intensity in which the highest fat oxidation rate occurs was determined in this exercise test for each subject. Oxygen uptake $\left(\mathrm{VO}_{2}\right)$ and carbon dioxide $\left(\mathrm{VCO}_{2}\right)$ production during the exercises were followed by respiratory gas analyzer and whole-body fat oxidation was calculated by indirect calorimeter equations. Subjects performed $45 \mathrm{~min}$ intermittent (IE) and continuous (CE) exercises in respiratory exchange ratio (RER) at intensity correspondent at the highest fat oxidation rate (Fat ${ }_{\max }$ ). The peak fat oxidation rate was equal to $40.6 \%$ of maximum oxygen consumption of subjects. The changes occurring with time in fat $(\mathrm{F}=20.67)$ and carbohydrate $(\mathrm{F}=19.44)$ oxidation rates were statistically significant $(\mathrm{P}<0.01)$. However, the changes of fat and carbohydrate $(\mathrm{CHO})$ oxidation with time did not show any statistically significant differences between the continuous and intermittent exercises $(\mathrm{P}>0.05)$. The results of the study indicate that the continuous and intermittent exercises performed at the exercise intensity ensuring maximum fat oxidation rate provide similar fat oxidation. Especially, for the individuals starting regular exercise applications newly, it can be said that similar positive results regarding fat oxidation can also be obtained by avoiding the insipidity of long lasting exercises and giving breaks.
\end{abstract}

Keywords: exercise; fat oxidation rate; cho oxidation; continuous exercise; intermittent exercise.

\section{Introduction}

One of the important energy resources of body is fat. They create problems unless they are exposed enough oxidation. The global increase in the prevalence of overweight and obesity is now reaching epidemic scale in both developed and developing countries (WHO, 2000). Therefore, researchers have researched whether the exercises done for a healthy life is suitable for its purpose or not for many years.

Treatments that prevent conditions like overweight and obesity are of considerable interest both to the general public and health-care professionals (Thompson et al, 1998). Probably the most important of these treatments is regular exercise that increases daily energy expenditure and fat

\footnotetext{
1 This work was produced from the master thesis.

2 Res. Assist. Dr., Gazi University, Faculty of Sports Science, Department of Coaching Education, gipekoglu@gazi.edu.tr

${ }_{3}^{3}$ Assist. Prof. Dr., Selcuk University, Faculty of Sports Science, Department of Sports Science, ssbalci@,selcuk.edu.tr
} 

intensity of maximal fat oxidation. Journal of Human Sciences, 13(3), 4604-4612. doi:10.14687/jhs.v13i3.4134

oxidation. In addition, it has been shown in athletes that after endurance training, fat oxidation at a given intensity is increased that coincides with increases in performance (Hickson et al, 1977; Holloszy and Coyle, 1984). Many factors influence substrate oxidation rates such as exercise duration, exercise intensity, gender, hormonal status, diet, cardiorespiratory fitness and body composition (Brooks and Mercier, 1994; Romijn et al, 1994; Venables et al, 2005; Abildgaard et al, 2013; Chu et al, 2014; Achten and Juekendrup, 2004; Bircher and Knechtle, 2004). Although there has been growing interest in understanding the independent roles of cardiorespiratory fitness and body fatness on health outcomes, their relative importance on Fat ${ }_{\text {max }}$ during exercise have not been fully elucidated (Florez and Castillo-Florez, 2012).

The frequency, intensity, and duration of an exercise are generally more focused on increasing energy expenditure than on increasing fat oxidation (Rojmin et al, 1993; Phillips et al, 1996; Balci, 2012). Even though there are many studies related to the effect of high intensity interval exercises (Sidossis et al, 1997; Coggan, 2000; Talanian et al, 2007; Trapp et al, 2008) on substrate oxidation, there are few effects of intermittent exercises done with moderate and low intensity in the literature. It is thought that the effect of taking a break in lengthy exercises on fat metabolism can enlighten experts who create exercise programs.

Therefore, the aim of the study was to determine the exercise intensity when the highest fat oxidation rate occurs and the rate of fat oxidation during continuous and intermittent acute exercise. The results of the research are thought to contribute to the preparation of exercise programs for individuals with excessive fat and diseases like obesity.

\section{Method}

\subsection{Population and sample selection}

Eleven healthy untrained men $(176.1 \pm 1.1 \mathrm{~cm}, 72.1 \pm 1.2 \mathrm{~kg}, 23.3 \pm 0.5$ years $)$ who don't smoke, volunteered to participate in this study (Table 2). Eating habits and the levels of physical activity of the participants were arranged by the instructions given before the tests. At the night before the tests, it was said to subjects that they shouldn't eat and drink anything except water after 9:00 pm and were asked to avoid drinking alcohol, tea, coffee before $24 \mathrm{~h}$ of each test.

\subsection{Exercise protocol}

The subjects came to the laboratory on 3 different days for i) anthropometric measurements and the incremental exercise test for the determination of $\mathrm{VO}_{2 \text { max }}$ and $\mathrm{Fat}_{\max }$; ii) a 45-min continuous exercise test at the intensity corresponding to $\mathrm{Fat}_{\max }$; iii) a 45 -min intermittent exercise (15 $\min \mathrm{x} 3$ bout, 5 min rest between bouts) test at the intensity corresponding to $\mathrm{Fat}_{\max }$. There were at least 3 days between the tests and warm up was done for 5 min before all tests.

\subsection{Measurements}

Subjects were weighed wearing nothing but their underwear. Weights and heights were measured with a beam balance scale and stadiometer to the nearest $0.1 \mathrm{~kg}$ and $0.5 \mathrm{~cm}$, respectively. Body mass index (BMI) was calculated by the weight in kilograms divided by the square of the height in meters. In all subjects' four skinfold thicknesses (biceps, triceps, subscapular, suprailiac) were measured in triplicate, by the same observer. Measurements were made on the right hand side of the body using a Holtain caliper and body fat percentage was calculated by Durnin and Womersley (1974) formula. 

intensity of maximal fat oxidation. Journal of Human Sciences, 13(3), 4604-4612. doi:10.14687/ihs.v13i3.4134

Oxygen uptake and carbon dioxide production during exercises were observed by a portable gas analysis system (Cosmed K4 b 2, Italy). Calibrations of air in the room, gases and analyzer turbine were done before each practice. Each test data was saved from the analyzer to a laptop. The collected data included: time, breathing frequency (Rf), tidal volume (Vt), ventilation (VE), oxygen consumption $\left(\mathrm{VO}_{2}\right)$, carbon dioxide production $\left(\mathrm{VCO}_{2}\right)$, heart rate $(\mathrm{HR})$, environmental temperature and pressure. Energy expenditure, and total $\mathrm{CHO}$ and fat oxidation rates were estimated from $\mathrm{VO}_{2}$ and $\mathrm{VCO}_{2}$ by using stoichiometric equations (Frayn, 1983).

CHO oxidation $(\mathrm{g} / \mathrm{min})=4.55 \mathrm{VCO}_{2}-3.21 \mathrm{VO}_{2}$

Fat oxidation $(\mathrm{g} / \mathrm{min})=1.67 \mathrm{VO}_{2}-1.67 \mathrm{VCO}_{2}$

The percentage of $\mathrm{CHO}$ and fat oxidation were calculated using the following equations (Dumortier et al, 2005):

$\%$ Fat $=[(1-$ RER $) / 0.29] * 100$

$\% \mathrm{CHO}=[(\operatorname{RER}-0.71) / 0.29] * 100$

Energy expenditure while resting was calculated by using the equation of Weir (1949). The average values for $\mathrm{VO}_{2}$ and $\mathrm{VCO}_{2}$ were calculated over the last $2 \mathrm{~min}$ for every stage of the modified Bruce treadmill test, and the Fat ${ }_{\max }, \% \mathrm{VO}_{2 \max }$ at which the highest fat oxidation observed, $\mathrm{VO}_{2}$ and $\mathrm{RER}$ at the Fat ${ }_{\text {max }}$ variables were identified (Acthen et al, 2003).

Subjects performed a graded exercise test commencing at $60 \mathrm{~W}$ to determine the peak $\mathrm{VO}_{2}$ $\left(\mathrm{VO}_{2 \max }\right)$ on, followed by $35 \mathrm{~W}$ increments every $3 \mathrm{~min}$ on the ergometer (Nordby et al, 2006). Exercise intensity corresponding to $F_{a t}{ }_{\max }$ was determined in this test for each subject. The test was ended when the heart rate reached the peak level, RER exceeded 1.1 value or subject didn't achieve 60 r.p.m.

\subsection{Research ethics}

The study was approved by Non-invasion Clinical Ethics Committee of Selcuk University Faculty of Physical Education and Sports Sciences, and a consent form was obtained from each subject.

\subsection{Evaluation data}

Statistical analyses were performed using SPSS for Windows (Chicago, IL, USA). Statistical significance was set at a $\mathrm{P}<0.05$ level and the data are expressed as mean $\pm \mathrm{SEM}$. The data were tested for normal distribution with the Kolmogorov-Smirnov test and for homogeneity of the variances with Levene's test. The statistical evaluation of the data was accomplished by using a twoway analysis of variance with repeated-measure design. The two factors $(2 \times 9)$ were exercise types (continuous and intermittent exercise) and the repeated measures (fat and $\mathrm{CHO}$ oxidation rate for each $5 \mathrm{~min}$ ). When the time effect was significant in the ANOVA of repeated measures, one-way analysis of the variance with post-hoc Bonforoni test was applied to identify the tests and/or times responsible for the difference. Paired t-tests were used to compare mean values between continuous and intermittent exercises. 
İpekoğlu, G., \& Balcı, S.. S. (2016). Comparison between continuous and intermittent submaximal exercise at the intensity of maximal fat oxidation. Journal of Human Sciences, 13(3), 4604-4612. doi:10.14687/ihs.v13i3.4134

\section{Results}

Table 1: Participants' characteristics and physiological parameters at Fat ${ }_{\text {max }}$ during graded exercise test $(\mathrm{n}=11)$

\begin{tabular}{lrcc}
\hline Variables & $\bar{X}$ & $\pm \mathbf{S}_{\mathbf{x}}$ & Min- Max \\
\hline Age (years) & $23.3 \pm 0.5$ & $21.0-27.0$ \\
Height $(\mathrm{cm})$ & 176.1 & \pm 1.1 & $171.6-182.0$ \\
Weight $(\mathrm{kg})$ & $72.1 \pm 1.2$ & $63,0-78.0$ \\
Body fat $(\%)$ & $16.2 \pm 0.7$ & $13.3-20.3$ \\
VO $_{2 \max }(\mathrm{ml} / \mathrm{kg} / \mathrm{min})$ & $38.6 \pm 1.4$ & $30.4-45.6$ \\
Fat $_{\max } \mathrm{RER}$ & $0.80 \pm 0.02$ & $0.7-0.9$ \\
\hline $\bar{X}$ & & \pm
\end{tabular}

$\bar{X} \pm \mathrm{S}_{\mathrm{x}}$; Arithmetic mean \pm standard error of the mean, $\mathrm{VO}_{2 \text { maks }}$; maximal oxygen consumption, Fat ${ }_{\max }$ RER; respiratory exchange ratio at the intensity corresponding to $\mathrm{Fat}_{\max }\left(\mathrm{VCO}_{2} / \mathrm{VO}_{2}\right)$.

Table 2: Differences in respiratory parameters, $\mathrm{CHO}$ and fat oxidation between the continuous and intermittent groups during exercises.

\begin{tabular}{lrlrl}
\multicolumn{1}{c}{ Variables } & CE mean & $\pm \mathbf{S}_{\mathbf{x}}$ & IE $\pm \mathbf{S}_{\mathbf{x}}$ & \multicolumn{1}{c}{$\mathbf{t}$} \\
\hline $\mathrm{Rf}(\mathrm{breaths} / \mathrm{min})$ & 24.93 & \pm 0.32 & $23.74 \pm 0.92$ & 1.09 \\
$\mathrm{VE}(\mathrm{L} / \mathrm{min})$ & 30.79 & \pm 0.72 & $32.84 \pm 1.17$ & -1.31 \\
$\mathrm{VO}_{2}(\mathrm{ml} / \mathrm{min})$ & 1121.50 & \pm 24.10 & $1213.23 \pm 46.48$ & -1.45 \\
$\mathrm{VCO}_{2}(\mathrm{ml} / \mathrm{min})$ & $983.12 \pm 19.64$ & $1056.03 \pm 41.98$ & -1.30 \\
$\mathrm{RER}\left(\mathrm{VCO} / \mathrm{VO}_{2}\right)$ & $0.88 \pm 0.01$ & $0.87 \pm 0.01$ & 0.39 \\
$\mathrm{HR}(\mathrm{beats} / \mathrm{min})$ & $113.76 \pm 2.14$ & $122.27 \pm 3.21$ & -1.95 \\
Fat oxidation $(\mathrm{gr} / \mathrm{min})$ & $0.23 \pm 0.02$ & $0.26 \pm 0.02$ & -0.98 \\
$\mathrm{CHO}$ oxidation $(\mathrm{gr} / \mathrm{min})$ & $0.87 \pm 0.05$ & $0.91 \pm 0.07$ & -0.45 \\
\hline
\end{tabular}

$\mathrm{S}_{\mathrm{x}}$; standard error of the mean, CE; continuous exercise, IE; intermittent exercise, $\mathrm{t}$; difference of means, Rf; respiratory volume, $\mathrm{VE}$; ventilation, $\mathrm{VO}_{2}$; oxygen uptake, $\mathrm{VCO}_{2}$; carbon dioxide production, $\mathrm{RER}$; respiratory exchange rate $\left(\mathrm{VCO}_{2} / \mathrm{VO}_{2}\right)$, $\mathrm{HR}$; heart rate.

Changes in $\mathrm{CHO}$ oxidation, fat oxidation, Rf, VE, RER and HR were not different between intermittent and continuous exercise groups $(\mathrm{P}>0.05)$ (Table 2).

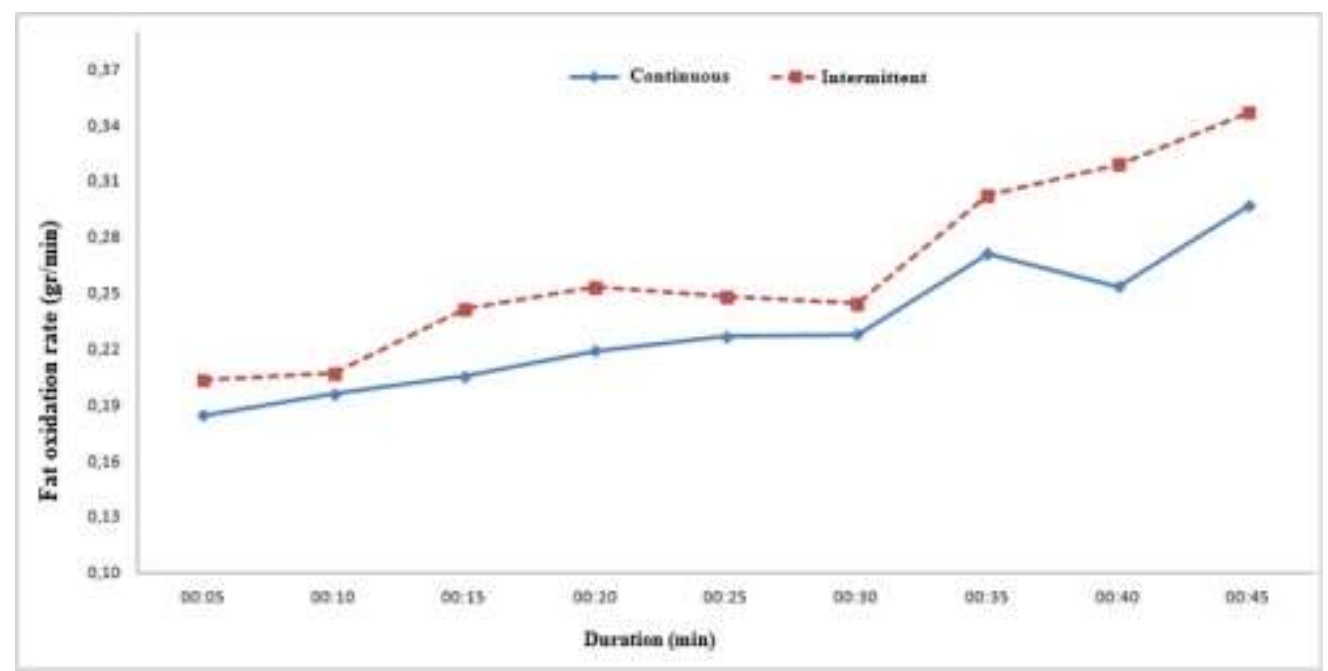

Figure 1: Changes in fat oxidation during continuous and intermittent exercises (gr/min)

The changes in fat oxidation for the 5 minute sections of the exercises were significant in the intermittent and continuous exercises $(\mathrm{F}=20.67 ; \mathrm{P}<0.01)$. The fat oxidation rate in the last $15 \mathrm{~min}$ 

intensity of maximal fat oxidation. Journal of Human Sciences, 13(3), 4604-4612. doi:10.14687/ihs.v13i3.4134

of the both exercise groups was significantly higher compared to the first $30 \mathrm{~min}(\mathrm{P}<0.01)$. Fat oxidation rates were similar during $45 \mathrm{~min}$ exercises for both groups $(\mathrm{F}=0.92 ; \mathrm{P}>0.05)$. Furthermore, fat oxidation rates were not different in both groups (time effect $\mathrm{F}=0.87$, timeexercise interaction $\mathrm{P}>0.05$ ) (Figure 1).

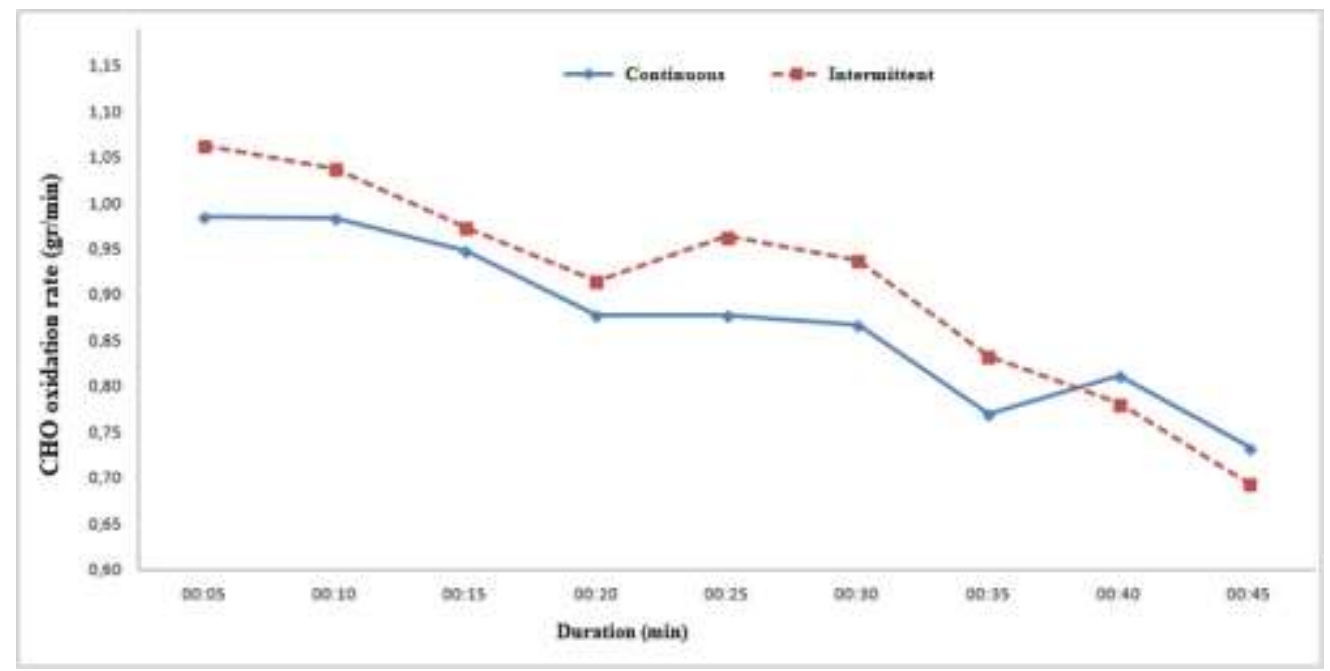

Figure 2: Changes in $\mathrm{CHO}$ oxidation during continuous and intermittent exercises (gr/min)

$\mathrm{CHO}$ oxidation rates calculated for the 5 minute sections of the exercises were statistically significant $(\mathrm{F}=19.44 ; \mathrm{P}<0.01)$. However, the change of $\mathrm{CHO}$ oxidation rate with time did not display any statistically significant differences between continuous and intermittent exercises (time effect $\mathrm{F}=0.87$, time-exercise interaction $\mathrm{P}>0.05)$. $\mathrm{CHO}$ oxidation rates were similar during $45 \mathrm{~min}$ exercises for both groups $(\mathrm{F}=0.21 ; \mathrm{P}>0.05)$ (Figure 2).

\section{Discussion}

It is important that the fat oxidation rate should be increased to regulate metabolism during exercises done for health. It is known that the energy used in moderate and high intensity exercises is mostly CHO. It was determined that maximal endurance exercises increase the fat oxidation rate considerably during submaximal exercises. Researches in which many subject involved support the knowledge that long lasting and continuous exercises increase fat oxidation during exercise thereby decrease the using $\mathrm{CHO}$ as energy source. Although studies were applied mostly on overweight men, it was observed that these exercises increase the fat oxidation rate on women, old and obese individuals (Acthen and Jeukendrup, 2004).

In the research carried out in connection with exercise types; with similar work-load when compared to bicycle ergometer with running exercise on treadmill, fat oxidation rate is considerably higher on exercise done on the treadmill (Acthen et al, 2003). Studies analyzing energy metabolism during exercises revealed that even though fat oxidation rate increases at the beginning of the exercise; when the intensity of the exercise gets increased, $\mathrm{CHO}$ oxidation rate increases much more. Therefore, in exercise programs aiming at decreasing the percentage of body fat, the type and the intensity of the exercise gains importance (Nordby, 2006). Thus, in this study, 45 minute continuous and intermittent aerobic exercises were done at the intensity of maximum level of fat oxidation that was determined as personal. The changes of these exercises at intervals of 5 minute were statistically researched and comparisons were made.

In this study, the peak fat oxidation rate is equal to $40.6 \%$ of maximum oxygen consumption of subjects. There are a lot of researches to determine the peak fat oxidation rate on individuals with 

intensity of maximal fat oxidation. Journal of Human Sciences, 13(3), 4604-4612. doi:10.14687/jhs.v13i3.4134

different ages, genders and training situations. It is stated that maximum oxygen consumption on untrained individuals VO2max is $47-52 \%$, on trained individuals within the range of $59-64 \%$ of exercise intensities peak fat oxidation speed was reached (Acthen and Jeukendrup, 2004; Pillard, 2007). Croci et al. (2014) reported that peak fat oxidation rate was $46 \%$ VO2max in overweight and $45 \%$ in lean males. Venables et al. (2005) carried out a research on 300 subjects whose age range is 18-65 on treadmill and stated that the maximal fat oxidation rate occurs when the exercise intensity is $44.9 \%$ for men and $51.9 \%$ for women.

Achten et al. (2002), applied on young trained cyclists to determine the exercise intensity needed to be applied to obtain the speed of maximum fat oxidation, it was figured out that in bicycle ergometer, exercise intensity applied three minutes $35 \mathrm{~W}$ load increment is in accordance with the determination of maximal fat oxidation rate of trained individuals. Also, it was stated that when the exercise intensity (59-65\%) of maximal fat oxidation is exceeded, the usage of $\mathrm{CHO}$ increases rapidly.

The present study, on the fat oxidation rate calculated in the 5 minute parts of exercise, it was seen that changes occurred in time are statistically important. While in both exercise practices the fat oxidation rate occurring in the last 15 minutes were significantly higher than the fat oxidation rate occurring in the first 30 minutes, the fat oxidation speed displayed similarities in continuous and intermittent exercises. Also, changes taking place in time during the fat oxidation rate didn't display a significant difference between continuous and intermittent exercises. In another study done in parallel with this, in continuous and intermittent exercises including similar work load, it was stated that there was no significant difference in terms of fat and $\mathrm{CHO}$ oxidation on energy expenditure (Achten et al, 2002). Essen et al. (1977) reported that a 60 minute continuous submaximal aerobic exercise practice and metabolic answers towards the exercise practices comprised of 15 seconds of practicing and 15 seconds of resting ranges done in similar workload and oxygen consumption were similar. In addition to this, when changes in substrate oxidation rates in bicycle ergometer at the level of $50 \%$ of 90 minute $\operatorname{maxVO}_{2}$ during continuous and intermittent exercises, it was figured out that there was no significant difference on total energy expenditure; however, in intermittent exercises the fat oxidation rate was lower than continuous exercises (Warren et al, 2009). On the other hand, Gerber et al. (2014) stated that more fat loss observed with the high intensity intermittent exercise when compared with continuous steady state exercise.

In spite of this, it is known that high intensity intermittent exercises generate fat acid oxidation more than continuous moderate exercises (Chilibeck et al, 1998). Although in continuous and intermittent exercise practices done with equal oxygen consumption, a difference wasn't figured out in total energy expenditure, there was a difference at the rates of used substrate, it was determined that in spite of the continuous exercise practice, in intermittent exercise practice fat oxidation rate was almost less then three times, despite this $\mathrm{CHO}$ oxidation rate displayed 1,5 times higher (Christmass et al, 1999). In another research, it was reported that although similar hormonal changes were seen in both moderate aerobic exercises applied in two sections and at once with an hour period, repetitive exercise applied in two sections proved clearer high fat oxidation than exercise applied at once (Goto et al, 2007). In the studies conducted on younger age groups, it was determined that short-time sprint, interval exercises led more fat oxidation than 30 minute intermittent exercise. Also, when considered the choices of participants, it was stated that shorttime interval exercises were preferred more (Crisp et al, 2012).

The present study has a few limitations. First, fat oxidation during exercise may be influenced by many factors (e.g., age, gender, body composition, activity duration, activity type, diet, and training status). Second, energy balance and macro nutrient composition of the diet may influence substrate 

intensity of maximal fat oxidation. Journal of Human Sciences, 13(3), 4604-4612. doi:10.14687/jhs.v13i3.4134

oxidation rates. The participants were informed about dietary measures and content the previous day before the tests (Jeukendrup and Wallis, 2005; Balci, 2012).

In the study, in the last 15 minutes of the intermittent exercises and only in the last 5 minutes of the continuous exercises, it was seen that fat oxidation rate was more dominant than carbohydrate in substrate oxidation rates. According to the results, it was seen that maximum fat oxidation was observed in the range of large exercise intensity $\left(25-60 \% \mathrm{MaxVO}_{2}\right)$ and when intensity needed for maximum fat oxidation is exceeded, the fat oxidation rate decreases considerably. It can be said that besides exercise intensity factors such as age, gender, type of exercise, content and amount of nutrition taken before and after the exercises, body composition can affect the fat and $\mathrm{CHO}$ oxidation rates in the process of recovery during and after the exercises.

\section{Conclusions and recommendations}

In this research, in the last 15 minutes of intermittent exercises and only in the last 5 minutes of continuous exercises, fat oxidation rate was higher than carbohydrate in substrate oxidation rates; it was seen that at submaximal level when exercises got extended, used energy source was formed mostly by fat. It drew the attention that in survey carried out in the literature search, intermittent aerobic exercises were preferred rather than continuous exercises not to be boring. Because of having acquired similar results in the fat oxidation rate, it is suggested that at exercise level in which maximal fat oxidation rate occurs, at least 45 minute and more intermittent exercises should be done to steer away from monotony and to increase the applicability of regular physical activities.

Factors affecting fat oxidation rates in exercise programs to prove positive changes at significant level on body composition should be taken into consideration. As a result of this study done in parallel with these factors, during intermittent and continuous exercises a significant difference on total energy expenditure and substrate oxidation rate was not found.

\section{Acknowledgements}

This work was produced from the master thesis and supported with Selcuk University Department of Scientific Research and Project (including research funding). The authors would like to thank all the subjects who participated in this study. The authors declare that they have no conflict of interest.

\section{References}

Abildgaard, J.; Pedersen, A.T.; Green, C.J.; Harder-Lauridsen, N. M.; Solomon, T. P.; Thomsen C. et al. (2013). Menopause is associated with decreased whole body fat oxidation during exercise. Am J Physiol Endocrinol Metab, 304(11): 1227-36.

Achten, J.; Gleeson, M.; Jeukendrup, A. E. (2002). Determination of the exercise intensity that elicits maximal fat oxidation. Med Sci Sports Exerc, 34: 92-7.

Achten, J., \& Jeukendrup, A. E. (2004). Optimizing fat oxidation through exercise and diet. Nutrition, 20: 716-27.

Achten, J., Venables, M. C., \& Jeukendrup, A. E. (2003). Fat oxidation rates are higher during running compared with cycling over a wide range of intensities. Metabolism, 52: 747-52.

Balci, S. S. (2012). Comparison of substrate oxidation during walking and running in normal-weight and overweight/obese men. Obesity Facts, 5: 327-38.

Balady, G. J. (2000). Acsm's Guidelines for Exercise: Testing and Prescription. Michigan, Lippincott Williams \&Wilkins. 

intensity of maximal fat oxidation. Journal of Human Sciences, 13(3), 4604-4612. doi:10.14687/ihs.v13i3.4134

Bircher, S., \& Knechtle, B. (2004). Relationship between fat oxidation and lactate threshold in athletes and obese women and men. J Sports Sci Med, 3: 174-81.

Brooks, G. A., \& Mercier, J. (1994). Balance of carbohydrate and lipid utilization during exercise: the "crossover" concept. J Appl Physiol, 76(6): 2253-2261.

Chilibeck, P. D., Bell, G. J., Farrar, R. P., \& Martin, T. P. (1998). Higher Mitochondrial fatty acid oxidation following intermittent versus continuous endurance exercise training. Can J Physiol Pharmacol, 76: 891-94.

Christmass, M. A., Dawson, B., Pasaretto, P., \& Arthur, P. G. (1999). A comparison of skeletal muscle oxygenation and fuel use in sustained continuous and intermittent exercise. Eur $J$ Appl Physiol, 80: 423-35.

Chu, L., Riddell, M. C., Schneiderman, J. E., Mccrindle, B. W., \& Hamilton, J. K. (2014) The effect of puberty on fat oxidation rates during exercise in overweight and normal-weight girls. $J$ Appl Physiol, 116(1): 76-82.

Crisp, N. A., Fournier, P. A., Licari, M. K., Braham, R., \& Guelfi, K. J. (2012). Adding sprints to continuous exercise at the intensity that maximises fat oxidation: Implications for acute energy balance and enjoyment. Metabolism, 61; 1-7.

Coggan, A. R., Raguso, C. A., Gastaldelli, A., Sidossis, L. S., \& Yeckel, C. W. (2000). Fat metabolism during high-intensity exercise in endurance-trained and untrained men. Metabolism, 49: 122-128.

Croci, I., Hickman, I.J., Wood, R.E., Borrani, F., Macdonald, G.A., \& Byrne, N.M. (2014). Fat oxidation over a range of exercise intensities: fitness versus fatness. Applied Physiology, Nutrition, and Metabolism, 39(12), 1352-59.

Dumortier, M., Thöni, G., Brun, J. F., \& Mercier, J. (2005). Substrate oxidation during exercise: impact of time interval from the last meal in obese women. Int J Obes, 29: 966-74.

Durnin, J. V., \& Womersley, J. (1974). Body fat assessed from total body density and its estimation from skinfold thickness: measurements on 481 men and women aged from 16 to 72 years. BrJ Nutr, 32: 77-97.

Essen, B., Hagenfeldt, L., \& Kaijser, L. (1977). Utilization of blood-borne and intramuscular substrates during continuous and intermittent exercise in man. J Appl Physiol, 265: 489-506.

Florez, H., \& Castillo-Florez, S. (2012). Beyond the obesity paradox in diabetes: fitness, fatness, and mortality. JAMA, 308(6): 619-20.

Frayn, K. N. (1983). Calculation of substrate oxidation rates in vivo from gaseous Exchange. J Appl Physiol, 55: 628-34.

Gerber, T., Borg, M. L., Hayes, A., \& Stathis, C. G. (2014). High-intensity intermittent cycling increases purine loss compared with workload-matched continuous moderate intensity cycling. European journal of applied physiology, 114(7): 1513-20.

Goto, K., Ishii, N., Mizuno, A., \& Takamatsu, K. (2007). Enhancement of fat metabolism by repeated bouts of moderate endurance exercise. J Appl Physiol, 102: 2158-64.

Hickson, R. C., Rennie, M. J., Conlee, R., Winder, W. W., \& Holloszy, J. O. (1977). Effects of increased plasma fatty acids on glycogen utilization and endurance. J Appl Physiol, 43: 829_ 833.

Holloszy, J. O., \& Coyle, E. F. (1984). Adaptations of skeletal muscle to endurance exercise and their metabolic consequences. J Appl Physiol, 56:831-838, 1984.

Jeukendrup, A. E., \& Wallis, G. A. (2005). Measurement of substrate oxidation during exercise by means of gas exchange measurements. International Journal of Sports Medicine, 26: 28-37.

Jeukendrup, A. E., \& Achten, J. (2001). Fatmax: A new concept to optimize fat oxidation during exercise. European Journal of Sport Science, 1: 1-5.

Nordby, P., Saltin, B., \& Helge, J. W. (2006). Whole-body fat oxidation determined by graded exercise and indirect calorimetry: a role for muscle oxidative capacity?. Scandinavian journal of medicine \& science in sports, 16: 209-214. 
İpekoğlu, G., \& Balc1, Ş. S. (2016). Comparison between continuous and intermittent submaximal exercise at the intensity of maximal fat oxidation. Journal of Human Sciences, 13(3), 4604-4612. doi:10.14687/jhs.v13i3.4134

Phillips, S. M., Green, H. J., Tarnopolsky, M. A., Heigenhauser, G. J. F., Hill, R. E., \& Grant, S. M. (1996). Effects of training duration on substrate turnover and oxidation during exercise. Journal of Applied Physiology, 81: 2182-91.

Pillard, F., Moro, C., Harant, I., Garrigue, E., Lafontan, M., Berlan, M., Crampes, F., De Glisezinski, I., \& Rivière, D. (2007). Lipid oxidation according to intensity and exercise duration in overweight men and women. Obesity, 15: 2256-62.

Romijn, J. A., Coyle, E. F., Sidossis, L. S., Gastaldelli, A., Horowitz, J. F., Endert, E., \& Wolfe, R. R. (1993). Regulation of endogenous fat and carbohydrate metabolism in relation to exercise intensity and duration. American Journal of Physiology-Endocrinology And Metabolism, 265: 380-91.

Sidossis, L. S., Gastaldelli, A., Klein, S., \& Wolfe, R. R. (1997). Regulation of plasma fatty acid oxidation during low- and high-intensity exercise. Am J Physiol Endocrinol Metab, 272: 106570.

Talanian, J. L., Galloway, S. D., Heigenhauser, G. J., Bonen, A., \& Spriet, L. L. (2007). Two weeks of high-intensity aerobic interval training increases the capacity for fat oxidation during exercise in women. Journal of applied physiology, 102: 1439-47.

Trapp, E. G., Chisholm, D. J., Freund, J., \& Boutcher, S. H. (2008). The effects of high-intensity intermittent exercise training on fat loss and fasting insulin levels of young women. International Journal of Obesity, 32: 684-91.

Thompson, D. L., Townsend, K. M., Boughey, R., Patterson, K., \& Basset, D. R. (1998). Substrate use during and following moderateand low-intensity exercise: Implications for weight control. Eur J Appl Physiol, 78:43-49.

Venables, M. C., Achten, J., \& Jeukendrup, A. E. (2005). Determinants of fat oxidation during exercise in healthy men and women: a cross-sectional study. J Appl Physiol, 98: 160-7.

Warren, A., Howden, E. J., Wiliams, A. D., Fell, J. W., \& Johnson, N. A. (2009). Postexercise Fat Oxidation: Effect of Exercise Duration, Intensity, and Modality. Int J Sport Nutr Exerc Metab, 19: 607-23.

Weir, J. D. V. (1949). New methods for calculating metabolic rate with special reference to protein metabolism. The Journal of Physiology, 109: 1-9.

World Health Organization (WHO). (2000). Obesity: preventing and managing the global epidemic. Report of a WHO consultation. World Health Organ Tech Rep Ser, 894: 16-20. 